\title{
Peningkatan Produktifitas Kerja Melalui Budaya Kerja dan Motivasi Kerja Pada PT Pelita Air Service Tangerang
}

\author{
Nurvi Oktiani ${ }^{1}$, Slamet Heri Winarno ${ }^{2}$ \\ ${ }^{1,2}$ Universitas Bina Sarana Informatika \\ e-mail: ${ }^{1}$ nurvi.nvk@bsi.ac.id, ${ }^{2}$ slamet.smh@bsi.ac.id

\begin{tabular}{ccc}
\hline Diterima & Direvisi & Disetujui \\
$22-01-2020$ & $21-02-2020$ & $25-02-2020$ \\
\hline
\end{tabular}

\begin{abstract}
Abstrak- Penelitian ini memiliki tujuan untuk menganalisis dan menguji tentang hubungan atau pengaruh dari budaya kerja dan motivasi kerja terhadap produktivitas kerja karyawan maskapai penerbangan PT Pelita Air Service Tangerang. Responden pada penelitian ini berjumlah 100 orang karyawan dari berbagai bagian di perusahan tersebut dengan menggunakan teknik purposive sampling. Desain penelitian menggunakan metode survei penelitian kuantitatif, wawancara dan kuesioner. Pengumpulan data dilakukan dengan penyebaran kuesioner menggunakan skala Likert. Teknik analisa menggunakan analisis deskriptif dan analisis inferensial menggunakan metode analisis regresi korelasi. Hasil penelitian menunjukkan bahwa budaya kerja dan motivasi kerja berpengaruh positif dan signifikan terhadap produktivitas kerja sebesar $71 \%$ sedangkan $29 \%$ dipengaruhi oleh faktor lain.
\end{abstract}

\section{Kata Kunci: Budaya Kerja, Motivasi Kerja, Produktivitas Kerja}

Abstract- This study aims to analyze and test the relationship or influence of work culture and work motivation on the work productivity of airline employees of PT Pelita Air Service Tangerang. Respondents in this study amounted to 100 employees from various parts of the company using purposive sampling techniques. The research design uses quantitative research survey methods, interviews and questionnaires. Data collection was carried out by distributing questionnaires using a Likert scale. The analysis technique uses descriptive analysis and inferential analysis using the correlation regression analysis method. The results showed that work culture and work motivation had a positive and significant effect on work productivity by $71 \%$ while $29 \%$ were influenced by other factors.

Keywords: Work Culture, Motivation, Productivity

\section{PENDAHULUAN}

Arah dan tujuan suatu perusahaan tidak akan terlepas dalam proses perkembangan dan pertumbuhan serta peningkatan profit yang tinggi untuk kelangsungan hidup perusahaan. Pertumbuhan dan perkembangan dari waktu ke waktu merupakan point yang paling penting dalam perkembangan suatu industri, hal ini dikarenakan rata-rata perubahan pertumbuhan dan perkembangan dalam suatu industri dapat merefleksikan pertumbuhan industri secara luas dan dengan adanya perubahan pertuumbuhan serta perkembangan yang lebih baik tersebut memberikan kesempatan serta peluang bagi industri ataupun perusahaan untuk lebih terbuka, menjadi leader dalam suatu persaingan industri selain hal tersebut dengan dapat mempengaruhi secara umum perkembangan pasar pada suatu negara, oleh sebab itu peningkatannya menjadi suatu trend dalam serta perencanaan teknik pertumbuhan dan pengembangan industri atau perusahaan yang membawa perusahaan pada level tertinggi dan memiliki pengalaman kemampuan dalam menghadapi persaingan yang lebih kompetitif, oleh sebab itu dalam suatu kebutuhan pasar serta persaingan yang terus terjadi dalam lingkungan industri seharusnya dipersiapkan suatu tujuan serta visi yang mengarah pada pengembangan salah satunya pada peningkatan produktivitas sebagai suatu cara agar perusahaan ataupun industri dapat menjalankan bisnisnya agar dapat bertahan dalam lingkungan yang kompetitif, berkembang dan tumbuh (SG, 2015)dalam suatu literatur khususnya bagi pengembangan produktivitas dalam berbagai sektor industri akan memberikan suatu peningkatan yang sangat esensial (penting) untuk peningkatan level peningkatan produk (barang dan jasa ) dalam suatu industri serta dapat membantu dalam mengatasi tantangan perusahaan proses pengelolaan perusahaan.(SG, 2015) adapun dalam penelitian ini melibatkan 35.000 orang dalam industri tersebut

Produktifitas karyawan merupakan suatu proses efesiensi dalam penilaian dalam suatu 
kelompok ataupun group, pada dasarnya produktivitas merupakan suatu komponen yang secara langsung memberikan dampak dalam pemberian profit bagi perusahaan, produktifitas dievaluasi dalam suatu periode tertentu , beberapa literatur menyatakan bahwa produktivitas tenaga kerja merupakan suatu konsep yang sangat sulit untuk diukur, pada defenisi yang mendasar dapat dinyatakan bahwa produk bahwa productivity tenaga kerja merupakan suatu konsep yang sangat sulit untuk diukur, pada defenisi yang mendasar dapat dinyatakan bahwa produk, adapun faktor - faktor yang mengidentifikasi produktifitas kerja diantaranya : (Nurmalasari, 2016)

1. Kualitas dan Kemampuan fisik karyawan yang meliputi tingkat pendidikan dan kepribadiannya , inisiatif dalam bekerja, sikap mental karyawan (rasa memiliki yang besar) serta etos kerja yang tinggi

2. Sarana Pendukung berupa

a) lingkungan kerja (dimana karyawan dapat merasakan suasana dalam lingkungan kerja dan maampu beradaptasi terhadap lingkungan pekerjaan, tingkat teknologi dan cara berproduksi sehingga dapat mengupdate tugas yang diberikan, keamanan dan kenyamanan dalam bekerja

b) Kesejahteraan karyawan yang terdiri atas pemberian kompensasi berdasarkan azas berkeadilan, kepastian atas kelangsungan pekerjaan

c) Supra sarana yang digunakan dalam produktifitas kerja karyawan yang meliputi hubungan industrial serta manajemen usaha karena dalam usaha peningkatan produktifitas sangat sensitif terhadap segala kegiatan industrial dan manajemen usaha

Oleh sebab itu melihat pentingnya pertimbangan akan peningkatan produktivitas perlu dipersiapkannya dan diperhatikan faktor-faktor serta strategi yang harus dilakukan dalam proses memaksimalkan pertumbuhan produktivitas dimana berbicara faktor-faktor yang mempengaruhi produktivitas kerja diantaranya adalah motivasi kerja dalam suatu guidelines (panduan) disebutkan bahwa dalam peningkatan produktivitas diantaranya (Attar, Gupta, \& Desai, 2012): pelatihan yang tepat bagi tenaga kerja, motivasi bagi bagi pekerja, penyediaan dan proses manajemen yang tepat sasaran, alur yang sistematik dalam bekerja, ketepatan, kejelasan dan tepat waktu, fasilatas dan lain- lain, dari peryataan ini dapat disimpulkan bahwa salah satu faktor yang mempengaruhi produktivitas kerja adalah bagaimana perusahaan dalam mengelola dan mengatur serta menjaga motivasi kerja karyawan, motivasi kerja merupakan hasil dari interaksi antara factor kesadaran atau faktor ketidaksadaran seperto intesitas dari keinginan ataupun kebutuhan, insetiv dan penghargaaan dari nilai suatu tujuan yang dicapai, serta adanya tingkat harapan dari individu, realitanya banyak dari tenaga kerja atau karyawan yang membutuhkan motivasi untuk peningkatkan performa mereka secara optimal, dan ini juga berhubungan dengan bagaimana karyawan dapat berkerja lebih baik lagi, oleh sebab itu beberapa tenaga kerja lebih baik dimotivasi dalam rangka memberikan suatu pengarahan dalam pencapaian prestasi kerja sehingga adanya titik temu antara tujuan personal dari karyawan itu sendiri serta tujuan yang hendak dicapai oleh perusahaan(Ghorbanhosseini, 2014)

Konsep dari motivasi pada dasarnya digunakan dalam konteks manajemen, dan motivasi diimplikasikan dan dilakukan oleh perorangan atau grup.

Beberapa Indikator dari motivasi kerja : (Mangkunegara, 2011)

1. Kebutuhan Fisiologis yang terdiri dari kelayakan dan keadilan dalam bekerja

2. Kebutuhan Rasa Aman yang terdiri atas perlindungan dari Ancaman Bahaya dan pemberian kompensasi

3. Kebutuhan Sosial yang terdiri dari team kerja yang solid, Adaptasi dalam kelompok unit kerja, toleransi, simpati, dan menghargai, interaksi social dengan rekan kerja,hubungan industrial

4. Kebutuhan Harga diri yang terdiri atas penghargaan terhadap prestasi kerja

5. Kebutuhan Aktualiasi yang terdiri atas pengembangan diri dan potensi diri, aktualisasi diri, pengembangan diri dan gagasan baru

Peningkatan Faktor lain yang mempengaruhi peningkatan produktivitas adalah melalui budaya kerja dalam lingkungan perusahaan. Budaya organisasi atau budaya kerja akan memberikan suatu dampak bagi perkembangan tingkah laku (behaviour) karyawan, adapun budaya kerja juga merupakan suatu subjek yang tercipta dalam upaya pengelolaan manajemen, sehingga akan memberikan dampak bagi motivasi dalam pengelolaan manajerial yang baik serta dalam upaya peningkatan kinerja atau prestasi kerja karyawan, selain itu budaya kerja akan memberikan suatu dampak yang esensial dalam memaksimalkan nilai-nilai dari human capital dan pada akhirnya budaya kerja juga dapat menciptakan suatu kompetensi manajemen kritik(Singh \& Mohanty, 2012) suatu tantangan yang terpenting dalam kegiatan manajemen untuk menentukan suatu tingkat efektifitas budaya dalam organisasi, dimana dalam upaya pengembangan budaya kerja hal yang harus diperhatikan juga berkenaan dengan dengan bagaimana performance karyawan dalam organisasi dalam melakukan pekerjaannya.(Ganta, 2014)

Karakteristik ataupun indikator dari budaya kerja (Wibowo, 2013)diantaranya : 
1. Innovation (inovasi) yang diindikasikan kreatifitas dalam bekerja, pengembanagan ide dan gagasan baru

2. Stability (stabilitas)yang terdiri dari adaptasi terhadap lingkungan pekerjaan, Penetapan aturan atau SOP (Standar Operational Procedure),

3. Orientation Toward people yang terdiri atas kepribadian atau behavior dari karyawan, dan pemberian penghargaan atas pencapaian prestasi kerja

4. Result Orientation yang terdiri dari Result Orientation yang terdiri dari pencapaian hasil kerja

5. Easygoingness yang terdiri dari indikator diantaranya iklim kerja yang sangat kondusif dan nyaman

6. Attention to detail (perhatian dari hal - hal yang mendetail) yang terdiri dari ketelitian dan kerapian

7. Collaborative Orientation yang terdiri dari kolaborasi dan kerjasama tim

Adapun perumusan masalah dan tujuan dalam penelitian ini adalah untuk menentukan :Sejauhmana Pengaruh serta hubungan antara budaya kerja dengan motivasi kerja serta pengaruhnya terhadap produktifitas kerja sehingga dapat diketahui seberapa besar pengaruh dan hubungan tersebut serta dampaknya bagi peningkatan produktifitas kerja dan dengan diketahuinya besaran pengaruh dan hubungan tersebut, penelitian ini dapat dijadikan referensi dan rujukan bagi perusahaan untuk mengambil langkah yang strategis dalam menentukan kebijakan yang berkaitan dengan penanganan produktifitas kerja

\section{Keterkaitan antara Budaya kerja dengan Motivasi Kerja}

Dalam beberapa kasus dan beberapa literatur menemukan bahwa budaya kerja merupakan suatu pembelajaran bagi organisasi yang dapat diasosiasikan dengan informasi dan teknologi, kepuasan kerja pegawai atau karyawan dan juga motivasi dalam transfer pembelajaran (.Dalam beberapa penelitian dengan mengunakan teori Herzberg menyatakan bahwa ada dua mootivasi kerja bagi karyawan yang dapat menilai tingkat kepuasan kerja, dan diambil suatu keputusan dimana budaya kerja merupakan elemen yang terpenting dalam meningkatan motivasi kerja yang akhirnya dapat memberikan dampak bagi tingkat atau derejat kepuasan kerja

Adapun halnya peryataan dari ahli bahwa suatu budaya kerja yang positif akan meningkatkan kinerja ataupun produktivitas karyawan dalam suatu organisasi, adapun dampak dari pelaksanaan budaya kerja dalam ruang lingkup kegiatan perusahaan akan dapat dihubungkan dengan motivasi dan produktivitas berdasarkan konteks level-level karyawan atau tenaga kerja., budaya kerja merupakan bagian terpenting dalam menentukan kesuksesan organisasi, adapun budaya organisasi merupakan suatu lingkungan dalam pekerjaan yang diformulasi melalui interaksi karyawan (SG, 2015) adapun budaya organisasi dapat dipelajari dalam lingkungan sosial sehingga dapat memberikan dampak dalam inovasi tingkah laku karyawan dalam suatu organisasi , adapun kombinasi dari tingkah laku , kepercayaan, moralitas serta kebiasaan anggota organisasi sangat penting dalam menciptakan budaya organisasi dan dapat memberikan alur ataupun proses dalam pembentukan faktor - faktor motivasi karyawan (Salah, 2016)

\section{Pengaruh Motivasi terhadap peningkatan} Produktivitas kerja

Level Motivasi dalam suatu lingkungan pekeerjaan memiliki pengaru langsung terhadap produktivitas karyawan, pekerja yang termotivasi dan memiliki ketertarikan terhadap pekerjaan mereka biaasanya akan membawa dan membangun tanggung jawab yang terbaik yang dapat mereka berikan, sehingga kemampuan dan produktifitas akan meningkat sebagai dampak dari motivasi tersebut, motivasi juga dapat didesain untuk dapat mengarahkan tingkah laku ataupun perilaku karyawan untuk dapat menghasilkan suatu kualitas pekerjaan(SG, 2015)

Karyawan dalam bekerja memiliki banyak kebutuhan serta keinginan yang ingin dicapai, oleh sebab itu kebutuhan dan keinginan tersebut akan diiringi dengan motivasi yang kuat serta usaha yang maksimal dalam melakukan suatu pekerjaan, dengan adanya motivasi tersebut akan memberikan dampak yang positif bagi peningkatan produktivitas kerja (Bawa, 2017), pada sustu perusahaan motivasi dan bagaimanapun juga produktivitas merupakan subjek yang menjadi perdebatan tanpa akhir dalam siklus operasional perusahaan, dan motivasi dapat didesain khusus menjadi variabel yang mempengaruhi performance maupun produktivitas kerja karyawan , motivasi dan produktivitas juga erat kaitannya dalam tingkah laku karyawan, dimana motivasi karyawan yang berada kondisi intrinsik dan extrinsik akan memberikan dampak peningkatan produktivitas karyawan seperti halnya pada proses promosi, peningkatan level prestasi karyawan dan lingkungan pekerjaan yang lebih baik (Conlin-hurd, 2017)

\section{Pengaruh Budaya Organisasi terhadap peningkatan Produktivitas kerja}

Beberapa penelitian yang telah dilakukan oleh akbari (Kibichii, Kiptum, \& Chege, 2016)dan uddin menemukan adanya korelasi yang positif antara budaya organisasi dan produktifitas, dan beberapa studi literatur yang lainnya yang dilakukan Ahiabor dan Gallagher oleh menyatakan bahwa budaya organisasi memberikan pengaruh langsung dalam produktivitas (Kibichii et al., 2016) 
Norma - norma dalam organisasi serta budaya dan nilai dalam suatu organisasi akan memberikan dampak yang cukup signifikan dan sepenuhnya bagi organisasi, budaya organisasi akan dapat melihat sejauh mana dalam menentukan keuntungan (profit) serta produktivitas yang akan dicapai oleh perusahaan oleh sebab itu apabila dalam suatu organisasi tingkah laku karyawan yang akan dikaitkan dan dikolaborasikan secara proffesional terhadap nilai dan kepercayaan yang berdasarkan faktor budaya organisasi dan norma akan memberikan pengaruh terhadap kepribadian (personality) dan produktivitas dari organisasi (Ahmed \& Shafiq, 2014)

\section{METODE PENELITIAN}

Desain penelitian yang dilakukan merupakan desain penelitian kuantitatif., pengujian dilakukan dengan mengunakan uji reliabilitas dan Uji Validitas serta uji asumsi klasik yang terdiri dari Uji asumsi klasik terdiri dari uji multikolinearitas, uji autokorelasi, uji Heteroskedasitas, uji normalitas dan uji regresi parsial, adapun pengambilan sample dilakukan secara purposive sampling yang merupakan teknik sampling non random sampling dimana peneliti menenttukan pengambilan sampel dengan cara menetapkan ciri - ciri khusus yang sesuai dengan tujuan penelitian sehingga dapat menjawab permasalahannya, dan data diperoleh melalui data primer dan data sekunder, dimana data primer diperoleh melalui penyebaran kuesioner dengan jumlah responden sebanyak 100 orang pada PT Pelita Air Service Tangerang, sedangkan data sekunder diperoleh dari referensi dan studi literature. (Widarjono, 2015)

\section{HASIL DAN PEMBAHASAN Uji Reliabilitas}

Uji reliabilitas merupakan suatu bentuk pengukuran dari indikator dari variable atau konstruk, suatu variable atau konstruk dinyatakan reliabel apabila peryataan tersebut konsisten atau stabil dari waktu ke waktu, pengukuran reliabilitas dilakukan dengan cara Repeated Measure atau pengukuran ulang, dan One Shot atau pengukuran sekali saja, adapun suatu konstruk dan variable dinyatakan reliabel apabila nilai Cronbach alfa > 0,70 (Ghozali, 2012) Hasil perhitungan menunjukkan nilai reliabilitas pada tabel 1.

\begin{tabular}{|c|c|c|}
\multicolumn{4}{c}{ Tabel 1. Reliabilitas } \\
\hline Variabel & $\begin{array}{c}\text { Nilai Cronbach } \\
\text { Alfa }\end{array}$ & Keterangan \\
\hline $\begin{array}{c}\text { Produktifitas } \\
\text { Kerja (Y) }\end{array}$ & 0.813 & Reliabel \\
\hline $\begin{array}{c}\text { Budaya Kerja } \\
\text { (X1) }\end{array}$ & 0.746 & Reliabel \\
\hline $\begin{array}{c}\text { Motivasi } \\
\text { Kerja (X2) }\end{array}$ & 0.837 & Reliabel \\
\hline
\end{tabular}

Sumber: Data diolah (2019)

Dari hasil tersebut diperoleh nilai Cronbach alfa yakni untuk variabel Produktifitas Kerja (Y) sebesar
0.813, nilai Cronbach alfa untuk budaya kerja (X1) sebesar 0.746, dan Motivasi kerja sebesar 0.837 sehingga dapat dinyatakan bahwa ketiga variabel diatas dinyatakan reliabel karena nilai Cronbach alfa lebih dari 0.70 .

\section{Uji Validitas}

Uji validitas merupakan suatu bentuk pengukuran kevalidan dari butir-butir pernyataan kuesioner sehingga dapat mengukur apa-apa yang diukur dalam butir kuesioner, untuk pengujian validitas ini dapat ditentukan dengan melihat korelasi antar skor butir peryataan dengan total skor konstruk atau variabel, dan uji signifikansi ini dilakukan dengan cara membandingkan nilai $R_{\text {hit }}$ dengan nilai $R_{\text {tabel }}$ dan untuk nilai Degree of Freedom (df: n-2) dengan fungsi n dinyatakan sebagai sample, untuk menguji apakah masing-masing indikator dari variabel tersebut valid ataupun tidak dapat dilihat dari perbandingan nilai Corrected Item-Total Correlation dengan perbandingan $R_{\text {tabel}}$, dimana jika nilai $R_{\text {hit }}$ lebih besar dari nilai dari $\mathrm{R}_{\text {tabel }}$ dan bernilai positif maka butir peryataan atau indikator tersebut dinyatakan valid, dan begitu sebaliknya jika nilai $R_{\text {hit }}$ lebih kecil dari nilai $\mathrm{R}_{\text {tabel }}$ dan bernilai negatif maka butir peryataan tersebut atau indikator dinyatakan tidak valid, berikut akan di jelaskan hasil pengolahan data validitas dari variabel produktifitas kerja.

Tabel 2. Nilai Validitas Produktivitas

\begin{tabular}{|c|c|c|}
\hline No & Indikator & $\begin{array}{l}\text { Corrected } \\
\text { item if Item } \\
\text { Deleted }\end{array}$ \\
\hline 1 & $\begin{array}{llr}\text { kepribadian dan pengembangan } \\
\text { wawasan } & \text { serta } & \text { Pendidikan } \\
\text { karyawan } & & \\
\end{array}$ & 0.559 \\
\hline 2 & berinisiatif dalam bekerja & 0.502 \\
\hline 3 & Belonging (Rasa Memiliki) & 0.519 \\
\hline 4 & Etos Kerja yang tinggi & 0.533 \\
\hline 5 & Adaptasi terhadap perubahan & 0.406 \\
\hline 6 & $\begin{array}{l}\text { Tingkat teknologi dan cara } \\
\text { berproduksi }\end{array}$ & 0.384 \\
\hline 7 & Keamanan dan kenyamanan & 0.547 \\
\hline 8 & $\begin{array}{l}\text { Pemberian } \quad \text { Kompensasi } \\
\text { berdasarkan azas berkeadilan }\end{array}$ & 0.444 \\
\hline 9 & $\begin{array}{llr}\text { Kapabilitas } & \text { dalam pengerjaan } \\
\text { Tugas, kepastian } & \text { atas } \\
\text { kelangsungan pekerjaan } & \\
\end{array}$ & 0.473 \\
\hline 10 & Hubungan industrial & 0.609 \\
\hline
\end{tabular}

Sumber: Data diolah (2019)

Dari data nilai validitas diatas, dapat dihitung untuk nili $\mathrm{R}_{\text {Tabel }}$ dengan $\mathrm{N}$ : Jumlah sample sebesar : 100 orang maka nilai df : $(100-2)$ : 98 dan nilai tingkat signifikansi untuk uji dua arah sebesar : df : (98, 5\%) : 0,1966, dibandingkan dengan nilai $\mathrm{R}_{\text {Hitung }}$ (Corrected Item if Item Deleted dari masing-masing indikator dapat dinyatakan valid dimana hal ini 
dikarenakan semua nilai Corrected Item Total Correlation berada diatas nilai $\mathrm{R}_{\text {tabel }}(0.1966)$

Demikian juga halnya untuk nilai validitas dari variabel budaya kerja (X1) dan Motivasi kerja (X2) dapat dinyatakan sebagai berikut:

Tabel 3. Validitas Budaya Kerja

\begin{tabular}{|l|l|c|}
\hline No & \multicolumn{1}{|c|}{ Indikator } & $\begin{array}{c}\text { Corrected } \\
\text { Item-Total } \\
\text { Correlation }\end{array}$ \\
\hline 1 & Kreatifitas dalam bekerja & 0.286 \\
\hline 2 & Ide dan Gagasan Baru & 0.388 \\
\hline 3 & $\begin{array}{l}\text { Adaptasi terhadap lingkungan } \\
\text { Pekerjaan }\end{array}$ & 0.368 \\
\hline 4 & $\begin{array}{l}\text { Penetapan aturan atau SOP } \\
\text { (Standar } \\
\text { Procedure) Operational }\end{array}$ & 0.219 \\
\hline 5 & Kepribadian & 0.469 \\
\hline 6 & $\begin{array}{l}\text { Pemberian Penghargaan atas } \\
\text { Prestasi kerja }\end{array}$ & 0.479 \\
\hline 7 & Peningkatan Prestasi Kerja & 0.523 \\
\hline 8 & $\begin{array}{l}\text { Iklim kerja yang Nyaman dan } \\
\text { Kondusif }\end{array}$ & 0.375 \\
\hline 9 & $\begin{array}{l}\text { Ketelitian dan Keterampilan } \\
\text { serta keahlian }\end{array}$ & 0.544 \\
\hline 10 & Kerjasama atau Team work & 0.452 \\
\hline
\end{tabular}

Sumber : Data diolah (2019)

Dari data validitas variabel Budaya kerja (X1) dapat disimpulkan bahwa perbandingan nilai $\mathrm{R}_{\text {tabel }}$ yakni sebesar 0,1966 dengan $\mathrm{R}_{\text {tabel }}$ (Corrected Item Total Correlation) dimana nilai $\mathrm{R}_{\text {Hitung }}$ masing - masing indikator lebih besar daripada $\mathrm{R}_{\text {tabel}}$, dan berdasarkan ketentuan diatas maka indikator tersebut dinyatakan valid. Begitu juga halnya untuk perhitungan validitas dari variabel Motivasi kerja (X2) dimana dapat digambarkan sebagai berikut:

Tabel 4. Validitas Motivasi Kerja (X2)

\begin{tabular}{|c|l|c|}
\hline No & \multicolumn{1}{|c|}{ Indikator } & $\begin{array}{c}\text { Corrected Item- } \\
\text { Total } \\
\text { Correlation }\end{array}$ \\
\hline 1 & $\begin{array}{l}\text { Kelayakan dan keadilan } \\
\text { dalam bekerja }\end{array}$ & 0.517 \\
\hline 2 & $\begin{array}{l}\text { Perlindungan, Kenyamanan } \\
\text { dalam bekerja }\end{array}$ & 0.517 \\
\hline 3 & pemberian kompensasi & 0.380 \\
\hline 4 & Team Kerja yang baik & 0.567 \\
\hline 5 & $\begin{array}{l}\text { Toleransi, simpati dan } \\
\text { menghargai }\end{array}$ & 0.554 \\
\hline 6 & $\begin{array}{l}\text { Interaksi sosial dengan } \\
\text { Rekan Kerja }\end{array}$ & 0.419 \\
\hline 7 & Hubungan Industrial & 0.387 \\
\hline 8 & Pencapaian Prestasi Kerja & 0.574 \\
\hline 9 & $\begin{array}{l}\text { Pengembangan diri dan } \\
\text { Potensi Diri }\end{array}$ & 0.622 \\
\hline 10 & aktualisasikan diri & 0.455 \\
\hline 11 & $\begin{array}{l}\text { Pengembangan ide dan } \\
\text { gagasan baru }\end{array}$ & 0.651 \\
\hline
\end{tabular}

Sumber : Data diolah (2019)

Dari hasil pengolahan data diatas untuk data validitas Motivasi kerja (X2)dapat dilihat untuk nilai Correted Item Total Correlation berada diatas nilai $\mathrm{R}$ hitung yakni berkisar antara $0.380-0.651$, sedangkan nilai $\mathrm{R}$ tabel adalah : 0.1966 oleh sebab itu maka nilai Rhitung lebih besar daripada nilai $\mathrm{R}$ tabel sehingga semua indikator diatas dinyatakan Valid

\section{Uji Multikolinearitas}

Uji multikolinearitas merupakan suatu uji yang bertujuan untuk menguji apakah suatu model regresi yang ditemukan terdapat suatu korelasi antar variabel bebas, untuk mendeteksi ada atau tidaknya nilai multikolinearitas dapat dilihat dari:

1. Jika nilai $\mathrm{R}^{2}$ yang dihasilkan oleh suatu estimasi model regresi yang bersifat empiris sangat tinggi

2. Melakukan analisis matrik korelasi antar variabelvariabel independen dimana apabila terdapat korelasi independent yang cukup tinggi yang umumnya diatas 0.90 maka hal ini dapat dinyatakan bahwa terjadi multikoliaritas

3. Multikolinearitas dapat dilihat dari nilai tolerance dan nilai Variance inflation Factor (VIF), nilai cut off yang umum dipakai untuk menunjukan adanya multikoliniaritas adalah nilai Tolerance kecil dari 0.10 atau sama nilai VIF besar dari dari 10 adalah

\begin{tabular}{|l|l|l|l|l|l|}
\hline \multicolumn{5}{|c|}{ Tabel 5. Hasil Multikolinearitas } \\
\hline \multirow{2}{*}{ Model } & \multicolumn{2}{|l|}{$\begin{array}{l}\text { Unstandardized } \\
\text { Coefficients }\end{array}$} & \multicolumn{2}{l|}{$\begin{array}{l}\text { Collinearity } \\
\text { Statistics }\end{array}$} \\
\cline { 2 - 6 } \multicolumn{2}{|c|}{} & B & $\begin{array}{l}\text { Std. } \\
\text { Error }\end{array}$ & $\begin{array}{l}\text { Toler } \\
\text { ance }\end{array}$ & VIF \\
\hline \multirow{2}{*}{1} & (Constant) & 6.959 & 2.54 & & \\
\cline { 2 - 6 } & $\begin{array}{l}\text { Budaya Kerja } \\
\text { (X1) }\end{array}$ & .156 & .092 & .419 & 2.385 \\
\cline { 2 - 6 } & $\begin{array}{l}\text { Motivasi } \\
\text { Kerja (X2) }\end{array}$ & .612 & .071 & .419 & 2.385 \\
\hline
\end{tabular}

Sumber : Data diolah (2019)

Hasil perhitungan nilai tolerance menunjukan bahwa diantara nilai Tolerance diantara variable independen seperti Budaya kerja (X1) dan Motivasi Kerja (X2) kurang dari 0,10 yang berarti tidak ada korelasi antar variable independent yang nilainya lebih dari 95\%, begitu juga dengan hasil perhitungan nilai Variance Inflation Factor (VIF) yang juga menunjukantidak ada salah satu variabel Independen yang memiliki nilai VIF lebih dari 10, jadi dapat disimpulkan bahwa tidak terjadinya gejala multikolinearitas antara variabel independent dalam model regresi kasus ini.(Widarjono, 2015)

\section{Uji Autokolerasi}

Uji autokorelasi merupakan suatu bentuk pengujian dari model regresi linear yang menyatakan adanya korelasi antara kesalahan pengangu pada suatu periode ( $\mathrm{t}$ ) dengan kesalahan pengangu pada periode t-1 sebelumnya, suatu model regresi yang baik adalah model regresi yang bebas dari autokorelasi adapun 
beberapa cara dalam menentukan atau mendeteksi autokorelasi diantaranya dengan a) Uji DurbinWatson (DW Test) merupakan suatu bentuk pengujiaan yang digunakan untuk autokorelasi tingkat satu dan mensyaratkan suatu intercept (konstanta) dalam suatu model regresi dimana jika:

1. Tidak ada autokorelasi : jika $0<\mathrm{d}<\mathrm{dl}$

2. Tidak ada autokorelasi Positif : $\mathrm{dl} \leq \mathrm{d} \leq \mathrm{du}$

3. Tidak ada Korelasi Negatif : $4-\mathrm{dl}<\mathrm{d}<4$

4. Tidak ada korelasi negatif : $4-\mathrm{du} \leq \mathrm{d} \leq 4$ - $\mathrm{dl}$

5. Tidak ada autokorelasi, positif ataupun negative : $\mathrm{du}<\mathrm{dl}<4-\mathrm{du}$

\begin{tabular}{|l|l|l|l|l|l|}
\hline \multicolumn{7}{|c|}{ Tabel 6. Model Summary } \\
\hline $\begin{array}{l}\text { Mod } \\
\text { el }\end{array}$ & $\mathrm{R}$ & $\begin{array}{l}\mathrm{R} \\
\text { Squ } \\
\text { are }\end{array}$ & $\begin{array}{l}\text { Adjusted } \\
\text { R Square }\end{array}$ & $\begin{array}{l}\text { Std. } \\
\text { Error of } \\
\text { the } \\
\text { Estimate }\end{array}$ & $\begin{array}{l}\text { Durbin- } \\
\text { Watson }\end{array}$ \\
\hline 1 & $.84^{\mathrm{a}}$ & .71 & .70 & 1.54 & 2.27 \\
\hline
\end{tabular}

a. Predictors: (Constant), Motivasi Kerja (X2), Budaya Kerja (X1)

b. Dependent Variable: Produktivitas (Y)

Sumber : Data diolah (2019)

Pada data tabel diatas nilai Durbin Watson sebesar 2,27 jika nilai ini dibandingkan dengan nilai signifikansi sebanyak $5 \%$, dan jumlah sampel : 100 orang, dan jumlah variabel indenpenden $(\mathrm{k}: 2)$ maka didapat nilai Durbin Watson batas atas (du):1,631 dan nilai (dl) : 1,715 dan nilai 4 - du : $(4-1.631)$ maka jika melihat tingkat syarat suatu intercept(konstanta) : dimana du $<\mathrm{d}<4$ - du : dimana $1,631<1.715<2.37$ maka dapat diartikan tidak ada autokorelasi positif dan autokorelasi negatif

\section{Uji Heteroskedasitas}

Uji Heteroskedasitas merupakan suatu pentuk pengujian dalam model regresi dimana pengujian heteroroskedasitas ini terjadi apabila variance dari residual satu pengamatan dengan pengamatan lainnya berbeda, adapun NonParametic Correlations (Ghozali, 2012)

\begin{tabular}{|c|c|c|c|c|c|}
\hline \multicolumn{6}{|c|}{ Tabel 7. Correlations } \\
\hline & & & $\begin{array}{l}\text { Buday } \\
\text { a } \\
\text { Kerja } \\
\text { (X1) }\end{array}$ & $\begin{array}{l}\text { Motiv } \\
\text { asi } \\
\text { Kerja } \\
\text { (X2) }\end{array}$ & $\begin{array}{l}\text { Unst } \\
\text { anda } \\
\text { rdize } \\
\text { d } \\
\text { Resi } \\
\text { dual }\end{array}$ \\
\hline \multirow{6}{*}{$\begin{array}{l}\text { Spea } \\
\text { rman' } \\
\text { s rho }\end{array}$} & \multirow{3}{*}{$\begin{array}{l}\text { Buday } \\
\text { a } \\
\text { Kerja } \\
\text { (X1) }\end{array}$} & $\begin{array}{l}\text { Correlation } \\
\text { Coefficient }\end{array}$ & 1.000 & $.758^{* *}$ & $\begin{array}{l}- \\
.012\end{array}$ \\
\hline & & $\begin{array}{l}\text { Sig. } \\
\text { tailed })\end{array}$ & . & .000 & .908 \\
\hline & & $\mathrm{N}$ & 100 & 100 & 100 \\
\hline & \multirow{3}{*}{$\begin{array}{l}\text { Motiv } \\
\text { asi } \\
\text { Kerja } \\
\text { (X2) }\end{array}$} & $\begin{array}{l}\text { Correlation } \\
\text { Coefficient }\end{array}$ & $.758^{* *}$ & 1.000 & $\begin{array}{l}. \\
.006 \\
\end{array}$ \\
\hline & & $\begin{array}{ll}\begin{array}{l}\text { Sig. } \\
\text { tailed })\end{array} & \text { (2- } \\
\end{array}$ & .000 & . & .952 \\
\hline & & $\mathrm{N}$ & 100 & 100 & 100 \\
\hline
\end{tabular}

Tabel 8. Uji Linearitas

\begin{tabular}{|l|l|l|l|l|l|}
\hline & $\begin{array}{l}\text { Unsta } \\
\text { ndardi }\end{array}$ & $\begin{array}{l}\text { Correlation } \\
\text { zed }\end{array}$ & -.012 & -.006 & $\begin{array}{l}1.00 \\
\text { Coefficient }\end{array}$ \\
\cline { 2 - 6 } & $\begin{array}{l}\text { Sig. (2- } \\
\text { Residu } \\
\text { al }\end{array}$ & tailed) & .908 & .952 &. \\
\cline { 2 - 6 } & $\mathrm{N}$ & 100 & 100 & 100 \\
\hline \multirow{2}{*}{}
\end{tabular}

**. Correlation is significant at the 0.01 level (2-tailed).

Sumber : Pengolahan data(2019)

\section{Uji Normalitas}

Pengujian normalitas bertujuan untuk mengujia apakah model regresi residual atau disini adalah variabel pengangu memiliki disitribusi Normal , adapun cara termudah dalam mendeteksi apakah residual tersebut berdistribusi normal atau tidak dapat dilakukan dengan cara analisis grafik dan analisis statistic, dalam analisis grafik melihat normalitas dengan cara melihat grafik histogram yang membandikan antara data observasi dengan distribusi yang mendekati distribusi normal , dimana asumsinya : jika data menyebar disekitar garis diagonal dan mengikuti arah garis diagonal atau grafik histogramnya menunjukan pola distribusi normal, maka asumsinya adalah normalitas, begitu juga sebaliknya jika datanya menyebar jauh dari garis diagonal atau grafiknya tidak menunjukan pola distribusi normal maka model tidak memenuhi asumsi normalitas.(Ghozali, 2012)

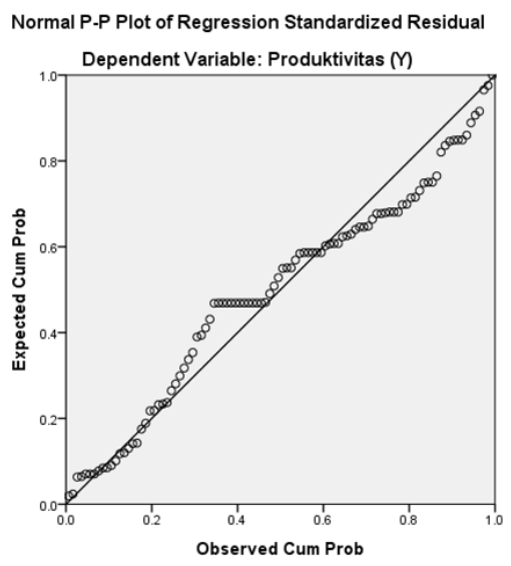

Gambar 1 : Grafik normalitas

Dari gambar 1 diatas dapat digambarkan bahwa pola grafik diatas menyebar disekitar garis diagonal dan mengikuti suatu arah diagonal maka dari analisis grafik dapat dinyatakan bahwa model dapat memenuhi asumsi normalitas

\section{Uji Linearitas}

Dalam uji linearitas, merupakan suatu bentuk pengujian yang dilakukan untuk melihat apakah spesifikasi model yang digambarkan sudah sesuai atau belum. 


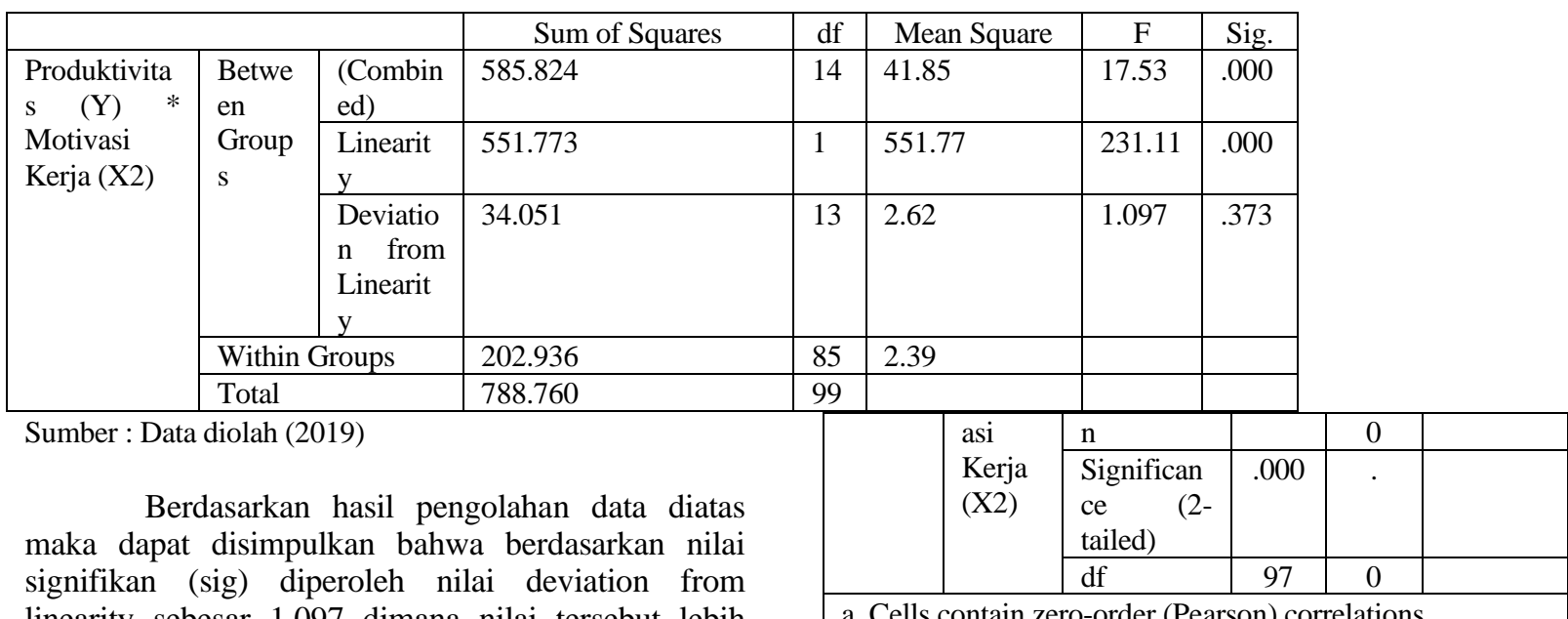
linearity sebesar 1,097 dimana nilai tersebut lebih besar daripada nilai 0.05 , maka dapat disimpulkan bahwa ada hubungan linear secara signifikan antara produktifitas dan motivasi kerja,, kemudian berdasarkan nilai $\mathrm{F}$ dimana dalam diperoleh nilai $F_{\text {hitung }}$ adalah $0.457<\mathrm{F}_{\text {tabel }}$ (dimana within group : 85 dan Deviation from linearity 13 maka didapat $\mathrm{F}_{\text {tabel }}$ sebesar 1,84 maka karena nilai $F_{\text {hitung }}$ lebih kecil dari nilai $F_{\text {tabel }}$ maka dapat disimpulkan bahwa terdapat hubungan linear secara signifikan antara variabel prokduktifitas kerja dan motivasi kerja.(Widarjono, 2015)

\section{Korelasi Parsial}

Merupakan jenis korelasi yang dilakukan untuk meninterpretasikan hubungan antar variabel

\begin{tabular}{|l|l|l|c|c|c|}
\hline \multicolumn{6}{|c|}{ Tabel 9. Correlations } \\
\hline \multicolumn{2}{|c|}{ Control Variables } & \begin{tabular}{c} 
Bud \\
aya \\
Kerj \\
a \\
\multicolumn{2}{|c|}{}
\end{tabular} & $\begin{array}{c}\text { Moti } \\
\text { vasi } \\
\text { Kerj } \\
\text { a }\end{array}$ & $\begin{array}{c}\text { Produkti } \\
\text { vitas (Y) } \\
\text { (X2) }\end{array}$ \\
\hline -none- \\
a
\end{tabular}

a. Cells contain zero-order (Pearson) correlations.

Sumber : Data diolah (2019)

Hasil pengolahan data diatas dapat disimpulkan bahwa pada bagian none-a dimana dinyatakan sebelum dapatkan hasil dari korelasi parsial menunjukan bahwa budaya dan motivasi kerja diperoleh nilai korelasi sebesar 0.762 dan nilai sig (0.000) , jika dibandingkan nilai tabel (r) dengan jumlah responden sebesar 100 orang : $N$ : $(100-2$ : 98) nilai tingkat kesalahan 0.05 maka diperoleh nilai tabel (r) :0.202, dapat dinyatakan : $0.762>0.202$ dan $0.000<0.05$ disimpulkan adanya tingkat keeratan antara budaya dan motivasi kerja , kemudian dalam korelasi parsial ini juga mengambarkan tingkat pengaruh budaya kerja dan motivasi kerja antara produktivitas yang dicapai oleh karyawan dengan melihat nilai correlation sebesar 0.455 dan signifikansi sebesar 0.000 dengan membandingkan $r$ tabel namun lebih dahulu diketahui degrees of freedom : df : N-K -1 : $100-3-1$ : 96 maka diperoleh $\mathrm{r}$ tabel : 0.202 dapat disimpulkan bahwa nilai signifikan $(0.000)<0.05$ dan nilai rhitung (0.455) > r tabel (0.202) maka disimpulkan bahwa variabel budaya kerja serta motivasi memiliki pengaruh yang kuat terhadap peningkatan produktivitas

\section{Persamaan Regresi}

Merupakan hubungan secara linear antara model persamaan yang menjelaskan hubungan satu variabel dependent dengan satu atau lebih variabel independent, disamping itu fungsi dari persamaan regresi ini adalah untuk mengetahui bagaimanakah arah serta hubungan antara variabel bebas atau independent dan variabel terikat (dependent).

\begin{tabular}{|c|c|c|c|c|c|c|}
\hline & & Tabel & . Coeff & & & \\
\hline & del & $\begin{array}{l}\text { Unst } \\
\text { d Co }\end{array}$ & $\begin{array}{l}\text { dardize } \\
\text { icients }\end{array}$ & $\begin{array}{l}\text { Stan } \\
\text { dard }\end{array}$ & $\mathrm{t}$ & Sig. \\
\hline & & B & $\begin{array}{l}\text { Std. } \\
\text { Error }\end{array}$ & Beta & & \\
\hline 1 & (Constant) & 6.96 & 2.54 & & 2.75 & .007 \\
\hline & $\begin{array}{l}\text { Budaya } \\
\text { Kerja (X1) }\end{array}$ & .156 & .092 & .143 & 1.69 & .095 \\
\hline
\end{tabular}




\begin{tabular}{|l|l|l|l|l|l|l|}
\hline $\begin{array}{l}\text { Motivasi } \\
\text { Kerja (X2) }\end{array}$ & .612 & .071 & .728 & 8.59 & .000 \\
\hline
\end{tabular}

Sumber : Data diolah (2019)

Pada tabel coefficient diatas dapat memberikan gambaran tentang bentuk persamaan regresi atau model yang dihasilkan dengan bentuk persamaan :

$\mathrm{Y}=6,96+0,156 \mathrm{X} 1+0,612 \mathrm{X} 2$

Dari persamaan diatas dapat dianalisis bahwa terdapat hubungan bersifat positif antara variabel-variabel yang diteliti. Jika budaya kerja dan motivasi kerja dinilai tidak ada maka nilai produktivitas kerja sebesar 6,96, dan jika kedua variabel independen nail 1 unit maka produktivitas akan bertambah sebesar 7,728 .

\section{KESIMPULAN}

Pada hasil pengolahan data atau output penelitian diperoleh kesimpulan bahwa terdapatnya korelasi parsial yang cukup erat antara budaya kerja dan motivasi kerja, serta terdapatnya pengaruh yang cukup signifikan antara budaya dan motivasi kerja terhadap peningkatan produktifitas kerja, namun apabila dilihat dari nilai persamaan regresi yang dihasilkan pada pengolahan data dari tabel coefficient diatas didapatkan bahwa motivasi kerja memberikan pengaruh yang lebih besar dibandingkan dengan budaya kerja oleh sebab itu kedepannya perlu diperhatikan kembali bagaimana peningkatan budaya kerja yang lebih baik lagi agar maksimalnya pencapaian Produktivitas kerja, adapun untuk implikasi hasil penelitian selanjutnya diharapkan untuk lebih memperdalam kajian bukan terhadap variabel - variabel yang lain yang dapat memperngaruhi peningkatan produktifitas kerja, misalnya variabel kompensasi, pelatihan atau variabe lainnya

\section{REFERENSI}

Ahmed, M., \& Shafiq, S. (2014). The Impact of Organizational Culture on Organizational Performance: Global Journal of Management and Business Research: A N Administration and Management, 14(3).

Attar, A. A., Gupta, P. A. K., \& Desai, P. D. B. (2012). A Study of Various Factors Affecting Labour Productivity and Methods to Improve It . IOSR Journal of Mechanical and Civil Engineering (IOSR-JMCE), 11-14. Diambil dari www.iosrjournals.org

Bawa, M. . (2017). Employee Motivation And Productivity: A Review Of Literature And Implications For Management Practice. International Journal of Economics, Commerce and Management, V(12), 662-673.
Conlin-hurd, A. (2017). Insight: The Four Basic Elements of Brand Strategy. Creative Revolution, (4), 26-28.

Ganta, V. C. (2014). Motivation In The Workplace To Improve The Employee Performance. International Journal of Engineering Technology, Management and Applied Sciences www.ijetmas.com, 2(6), 221-230.

Ghorbanhosseini, M. (2014). The Effect Of Organizational Culture, Teamwork And Organizational Development On Organizational Commitment: The Mediating Role Of Human Capital. International Journal of Engineering Technology, Management and Applied Scie, 2(6), 221-230.

Ghozali, I. (2012). Aplikasi Analisis Multivariat dengan Program IBM SPSS 20 Edisi 6. Semarang: Badan Penerbit Universitas Diponegoro.

Kibichii, K. E., Kiptum, K. G., \& Chege, P. K. (2016). Effects of Performance Management Process on Employee Productivity: A Survey of Commercial Banks in Turkana County. IOSR Journal of Business and Management (IOSR-JBM), $\quad$ 18(11), 52-64. https://doi.org/10.9790/487X-1811045264

Mangkunegara, A. P. (2011). Manajemen Sumber Daya Manusia Perusahaan. Bandung: PT Remaja Rosdakarya.

Nurmalasari. (2016). Dampak Kompensasi Terhadap Peningkatan Produktivitas Kerja Karyawan Pada PT. Pasifik Jaya Mandiri Pontianak. Evolusi, 4(2), 53-63.

Salah, M. R. (2016). The Impact of Training and Development on Employees Performance and Productivity " A case Study of Jordanian Private Sector transportation companies located in the Southern region 0 ... International Journal of Management Sciences and Business Research, 5(7).

SG, H. (2015). Productivity, Efficiency \&Quality. Partner Africa. Diambil dari doi:10.4172/2315- $\quad 7844.1000160$ https://\%0Awww.omicsonline.org/openaccess/the-impact-of-training-anddevelopment-on-workers-productivity-23157844-1000160.php?aid=59847

Singh, R., \& Mohanty, M. (2012). Impact of Training Practices on Employee Productivity : A Comparative Study. Interscience Management Review (IMR), 2(2), 87-92.

Wibowo. (2013). Budaya Organisasi (Sebuah Kebutuhan Untuk Meningkatkan Kinerja Jangka Panjang). Jakarta: PT RajaGrafindo Persada.

Widarjono, A. (2015). Analisis Multivariat Terapan dengan Program SPSS, AMOS, dan 
SMARTPLS Edisi Kedua. Yogyakarta: UPP STIM YKPN. 